\title{
Macro Risk Measurement Model of Commercial Bank Project Based on Multivariate Copula Function
}

\author{
Zhanjiang $\mathrm{Li}^{*}$ \\ College of Economics and Management, Inner Mongolia Agricultural University, No.306 ZhaoWu Da Road, \\ Saihan District, Hohhot, China. \\ * Corresponding author. Tel.: 15049121977; email: lizhanjiang582@163.com \\ Manuscript submitted August 1, 2016; accepted September 26, 2016. \\ doi: 10.17706/ijeeee.2016.6.4.220-226
}

\begin{abstract}
It is of great significance to measure the project risk of commercial bank investment while the bank is unable to obtain the full information of the project. The macro risk of project is shown through 3 risk factors, namely, government risk, industry risk, and policy risk. A measurement model of project macro risk based on the insufficient information is built in this paper. The innovation and feature of this paper come in two ways. First, the function relationship among the project risk factors is determined through Multivariate Copula Function. The large sample data of project risk factors are generated through Monte Carlo Simulation. Thus, the large sample data of risk factors can be obtained, which makes up for the deficiency of inaccurate weight of small sample. Second, the weight of each risk factor is determined through the mean square error method. Therefore, the macro risk of project can be measured.
\end{abstract}

Key words: Project macro risk, risk measurement, multivariate copula function, mean square error.

\section{Introduction}

As the risk measurement of commercial bank project is an important part of risk management in banking, it is urgent to carry out studies on the measurement of project macro risk, especially when the commercial bank is unable to obtain the specific information of project.

Current situation of the risk measurement of commercial bank project has the following two aspects.

1) Qualitative research on project risk. One of the most representative researches, conducted by Robert and Tiong [1], proposed that the risk of project would be affected by the support the bank got from government. Stand \& Poor's [2] discussed the main risk factors which would impact the risk of project in report. Deng Chao [3] established an evaluation index system of credit risk.

2) Quantitative research on project risk. Gatti [4] calculated the credit default risk of project through the value at risk. Bu-Qammaz et al. [5] built a risk assessment model on the basis of Analytic Network Process. Shan Xiaoli and Dai Dashuang [6] established a project financing model through the use of statistical techniques. Ulucan and Atıcı [7] studied the efficiency of the social risk of World Bank project through Data Envelopment Analysis.

Limitations to the previous researches: the previous studies can only be used to measure the project risk on the basis of the full financial information of project. In other words, the researches on the measurement of project risk are quite limited while the commercial bank is unable to get the full information of project.

In order to solve the above mentioned problem, this paper firstly uses three risk factors to reflect the project macro risk. Secondly, this paper applies multivariate Copula Function to get the large sample data of 
risk factors. Finally, the macro risk of project is measured by weighted model of risk factors.

This paper consists of six sections including introduction, measurement principle of project risk, analysis and grading of risk factors, sample augment via multivariate copula function, measurement model of project macro risk, establishment of project macro risk measurement model.

\section{Measurement Principle of Project Risk}

\subsection{Research Questions}

According to the sources of project risk, project risk can be classified into two types, namely project macro risk and project micro risk. In this paper, the project macro risk refers to government risk, industry risk, and policy risk. Whereas, the project micro risk refers to investment risk and the credit risk.

It is urgent to carry out studies on how to measure project macro risk through observable macro risk indices of project while the commercial bank is unable to get the full information of project.

\subsection{Problems in the Measurement of Project Risk}

1) Problem One: generate large sample according to the limited small sample of risk factors.

2) Problem Two: determine the quantitative relation among the 3 risk factors which show the macro risk of project, i.e., wi $(i=1,2,3)$.

\subsection{Solution to the Problems}

1) Solution to Problem One

The macro risk of project can be shown through the Government Risk R1, Industry Risk $\mathrm{R}_{2}$, and Policy Risk $\mathrm{R}_{3}$. The function relationship among the risk factors is determined through multivariate Copula Function.

2) Solution to Problem Two

According to the 3 macro risk factors of project, the Project Macro Risk Rp can be expressed as:

$$
R_{\mathrm{p}}=f\left(R_{1}, R_{2}, R_{3}\right)
$$

\section{Analysis and Grading of Risk Factors}

\subsection{Analysis of Risk Factors}

1) Government Risk $R_{1}$. The Government Risk R1 shows the macro risk of project with much support from government [1], [2].

2) Industry Risk $R_{2}$. The Industry Risk $R_{2}$ shows the macro risk of project with different industry prosperity indices [1], [2].

3) Policy Risk $R_{3}$. Policy Risk $R_{3}$ shows the macro risk of project with different policies[1-2].

\subsection{Grading of Risk Factors}

1) Standard Formula

The standard formula [8] of positive index is:

$$
R=\frac{r_{i}-\min \left(r_{i}\right)}{\max \left(r_{i}\right)-\min \left(r_{i}\right)} \times 0.5+1
$$

The standard formula [8] of negative index is: 


$$
R=\frac{\max \left(r_{i}\right)-r_{i}}{\max \left(r_{i}\right)-\min \left(r_{i}\right)} \times 0.5+1
$$

It should be pointed out that, in order to make sure that the mean-square-error weighting method will work when the index is 0 , the normalized interval of index in this paper is $[1,1.5]$.

2) Grading of Government Risk

The project types are listed in the 1st column of Table 1 and the support the bank gets is listed in the 2nd column of Table 1 . The values of Government Risk $\mathrm{R}_{1}$ obtained by expert scoring method are listed in the 3rd column of Table 1.

Table 1. Government Risk $\mathrm{R}_{1}$

\begin{tabular}{cccc}
\hline Serial number & (1) Project type & (2) Support & (3) $R_{1}$ \\
\hline 1 & National key project & Greatest & 1.0 \\
$\ldots$ & $\ldots$ & $\ldots$ & $\ldots$ \\
5 & Other projects & Smaller & 1.5 \\
\hline
\end{tabular}

3) Grading of Industry Risk $R_{2}$

The industry prosperity index adopted in this paper is substituted by the business climate index released by the National Bureau of Statistics of China each quarter (http://www.stats.gov.cn/.2003-2014). The Industry Risk $\mathrm{R}_{2}$ is measured through the predicated value of time series of business climate index due to the delay in the releasing of business climate index.

Let $x_{M}$ be the maximum of the time series of the prosperity index of a certain industry, $x_{A}$ be the mean value, and $x_{m}$ be the minimum. According to PERT Decision-making Method, the Predicted Value P of the industry prosperity index is [8]:

$$
P=\left(x_{M}+x_{A}+x_{m}\right) / 6
$$

The Predicted Value P of industry prosperity index is worked out by Formula (4) and is listed in the 1st row of Table 2. The Industry Risk R2 listed in the 3rd column of Table 2 is obtained by Formula (3).

Table 2. Industry Risk $\mathrm{R}_{2}$

\begin{tabular}{cccc}
\hline Serial number & (1) Industrial classification & $(2) P$ & $(3) R_{2}$ \\
\hline 1 & All industries & 129.73 & 1.236 \\
$\ldots$ & $\ldots$ & $\ldots$ & $\ldots$ \\
9 & Lodging and catering industry & 104.64 & 1.500 \\
\hline
\end{tabular}

4) Grading of Policy Risk $R_{3}$

The industry categories are listed in the 1 st column of Table 3 . The values of the policy risk obtained through the expert scoring method are given in the 2 nd column of Table 3.

Table 3. Policy Risk $\mathrm{R}_{3}$

\begin{tabular}{clc}
\hline Serial number & \multicolumn{1}{c}{ (1) Industry categories } & (2) $R_{3}$ \\
\hline 1 & Category One: restrict or eliminate & 1.5 \\
2 & Category Two: support & 1.0 \\
3 & Category Three: other industries & 1.2 \\
\hline
\end{tabular}

\section{Sample Augment via Multivariate Copula Function}




\subsection{Fitting of Marginal Distribution}

Let $u_{k}$ be the marginal distribution function sequence of $\operatorname{Risk} \operatorname{Rk}(\mathrm{k}=1,2,3)$. Then the calculation formulae of $u_{k}$ are [9]:

$$
u_{k}(i)=\frac{1}{n} \sum_{j=1}^{n} \Phi\left(\frac{R_{k i}-R_{k j}}{h_{k}}\right)
$$

where $n$ is the sample size, $\Phi(\cdot)$ is the standard normal distribution function, $R_{\mathrm{ki}}$ is the values of Sample $i$ of risk $R_{\mathrm{k}}$, and $h_{k}$ is smoothing parameters.

The calculation formulae of Smoothing Parameters $h_{\mathrm{k}}$ is [9]:

$$
h_{k}=1.06 n \sqrt[-0.2]{\frac{1}{n-1} \sum_{i=1}^{n}\left(R_{k i}-\overline{R_{k}}\right)^{2}}
$$

\subsection{Multivariate Copula Function Fitting}

In order to fit the multivariate joint distribution of risk factors, the multivariate normal Copula Function is used in this paper. The expression of multivariate normal Copula Function is [9]:

$$
c=\int_{-\infty}^{\Phi^{-1}\left(u_{1}\right)} \int_{-\infty}^{\Phi^{-1}\left(u_{2}\right)} \int_{-\infty}^{\Phi^{-1}\left(u_{3}\right)}|\rho|^{-\frac{1}{2}} \exp \left(-\frac{1}{2} \zeta^{\prime}\left(\rho^{-1}-I\right) \zeta\right) d u_{1} d u_{2} d u_{3}
$$

where $\rho$ is the correlation coefficient matrix of $u_{1}, u_{2}$ and $u_{3}, \zeta$ is the column vector, and $I$ is unit matrix.

\subsection{Monte Carlo Simulation}

In order to get the large sample date of risk factors, Monte Carlo Simulation is performed by the Copula Function (7). The random sequence of multivariate normal Copula Function is generated through Monte Carlo Simulation and then the large sample data can be obtained.

\section{Measurement Model of Project Macro Risk Rp}

1) Calculation Formula of Project Macro Risk Rp

The project macro risk is measured through the linear combination of the 3 risk factors. The Project Macro Risk $R_{\mathrm{p}}$ is:

$$
R_{\mathrm{p}}=w_{1} R_{1}+w_{2} R_{2}+w_{3} R_{3}
$$

2) Calculation of Weight Coefficients $w_{1}, w_{2}$ and $w_{3}$

Let $s_{k}$ be the sample standard deviation of risk factor $k$, then $w_{k}(k=1,2,3)$ is:

$$
\boldsymbol{W}_{k}=\boldsymbol{S}_{k} / \sum_{k=1}^{3} \boldsymbol{S}_{k}
$$

In Formula (9), the standard weight coefficient of risk factors is obtained through the mean-square-error objective weighting method. 


\section{Establishment of Project Macro Risk Measurement Model}

Since the measurement model of project macro risk is not established, the aim of this section is not an application example, but establishment of project macro risk measurement model.

If we only use the samples collected from such media to measure weight values, weight values will be unstable and inaccurate as change of the sample. To avoid the drawback of small samples, this paper uses multivariate copula function to get a large sample and applies this large sample to measure weight values.

Stability test of weight values shows that when the sample is greater than the number 962 , the weight value is stable [10]. Due to the fact that the sample number of this paper is 10,000 , the weight value is stable.

\subsection{Project Data}

In order to reveal the fixed importance of three risk factors, this paper firstly uses project data in Table 4 to measure functional relationship of risk factors. Then this paper uses a large sample obtained from multivariate copula function to measure the fixed importance of three risk factors. The fixed importance shows that no matter sample numbers and sample fluctuations, the important degree of three risk factors is stable.

The 72 loan projects between 2006 and 2014 are listed in the 1st, 2nd, and 3rd columns of Table 4. All the information of these loan projects comes from such media as People's network (http:// www.people.com.cn) and NetEase (http:// www. money.163.com).

According to the information in the $1^{\text {st }}, 2^{\text {nd }}$, and $3^{\text {rd }}$ of Table 4 , the values of Government Risk $R_{1}$, Industry Risk $R_{2}$, and Policy Risk $R_{3}$ obtained through Tables 1,2 and 3 are listed in the $4^{\text {th }}, 5^{\text {th }}$, and $6^{\text {th }}$ columns of Table 4.

Table 4. The Data of Project and Risk Factor

\begin{tabular}{cccccccccc}
\hline $\begin{array}{c}\text { Serial } \\
\text { numb } \\
\text { er }\end{array}$ & $\begin{array}{c}(1) \\
\text { Project name }\end{array}$ & $\begin{array}{c}(2) \\
\text { Project type }\end{array}$ & $\begin{array}{c}(3) \\
\text { Industry }\end{array}$ & $\begin{array}{c}(4) \\
R_{1}\end{array}$ & $\begin{array}{c}(5) \\
R_{2}\end{array}$ & $\begin{array}{c}(6) \\
R_{3}\end{array}$ & $\begin{array}{c}(7) \\
u_{1}\end{array}$ & $\begin{array}{c}(8) \\
u_{2}\end{array}$ & $\begin{array}{c}(9) \\
u_{3}\end{array}$ \\
\hline 1 & $\begin{array}{c}\text { Huangpu-River-crossing } \\
\text { construction project }\end{array}$ & $\begin{array}{c}\text { Provincial } \\
\text { key project }\end{array}$ & $\begin{array}{c}\text { Communication } \\
\text { and transportation }\end{array}$ & 1.1 & 1.439 & 1.2 & 0.166 & 0.778 & 0.491 \\
$\ldots$ & $\ldots$ & $\ldots$ & $\ldots$ & $\ldots$ & $\ldots$ & $\ldots$ & $\ldots$ & $\ldots$ & $\ldots$ \\
72 & $\begin{array}{c}\text { Wujiang East Taihu Lake } \\
\text { construction project }\end{array}$ & $\begin{array}{c}\text { Key project } \\
\text { of county }\end{array}$ & All industries & 1.3 & 1.427 & 1.0 & 0.486 & 0.183 & 0.211 \\
\hline
\end{tabular}

\subsection{Sample Augmented through Copula Function}

1) Fitting of Marginal Distribution

Parameter $h_{1}=0.176, h_{2}=0.025, h_{3}=0.137$ are obtained by Formula (6) and marginal fitted value $u_{1}, u_{2}, u_{3}$ are filled in the $7^{\text {th }}-9^{\text {th }}$ column of Table 4 by Formula (5).

2) Monte Carlo Simulation

By Formula (7), the data of the 10,000 samples of the 3 risk factors obtained through the Monte Carlo Simulation are listed in the $1^{\text {st }}-10,000^{\text {th }}$ rows of Table 5 .

\subsection{Measurement Model of Project Macro Risk Rp}

1) Calculation of the Weight $w_{\mathrm{k}}$ of risk factor

The sample standard deviations $s_{k}$ of the risk factors from Project 1 to Project 10,000 in Table 5 are listed in the $10,001^{\text {st }}$ row of Table 5. The Weight $w_{1}, w_{2}$ and $w_{3}$ of the risk factors is obtained by Formula (9). The results are filled in the $10,002^{\text {nd }}$ row of Table 5 . 
Table 5. Large Sample Data and the Weight of Risk Factor

\begin{tabular}{ccccc}
\hline Serial number & (1)Project name & (2)Government Risk $R_{1}$ & (3)Industry Risk $R_{2}$ & (4)Policy Risk $R_{3}$ \\
\hline 1 & Project 1 & 1.500 & 1.486 & 1.000 \\
$\cdots$ & $\cdots$ & $\cdots$ & $\ldots$ & $\cdots$ \\
10000 & Project 10000 & 1.500 & 1.438 & 1.200 \\
10001 & Standard deviation $s_{\mathrm{k}}$ & 0.176 & 0.069 & 0.137 \\
10002 & Weight $w_{\mathrm{k}}$ & 0.461 & 0.180 & 0.359 \\
\hline
\end{tabular}

2) Macro Risk Measurement Model of Project

The Project Macro Risk $R_{\mathrm{p}}$ can be obtained by formula (8). Model of $R_{\mathrm{p}}$ is:

$$
R_{\mathrm{p}}=0.461 \times R_{1}+0.180 \times R_{2}+0.359 \times R_{3}
$$

\section{Conclusion}

According to the weight of risk factors calculated through large sample, the importance of the 3 risk factors from high to low is: Government Risk $R_{1}\left(w_{1}=0.461\right)$, Policy Risk $R_{3}\left(w_{3}=0.359\right)$, and Industry Risk $R_{2}$ $\left(w_{2}=0.180\right)$.

First, the function relationship among risk factors is determined through Multivariate Copula Function. The large sample data of risk factors are generated through Monte Carlo Simulation. Second, the weight of each risk factor is determined through the mean square error method. So, the macro risk of project can be measured.

The future research trend is to construct a rating model of project macro risk for commercial bank.

\section{Acknowledgment}

The research is supported by the China Postdoctoral Science Foundation (2015M582754XB), Natural Science Foundation of Inner Mongolia Autonomous Region of China (2016MS0714) and National Natural Science Foundation of China (71171031).

\section{References}

[1] Robert, L. K. (2000). Positive management of differences for risk reduction in bot project. Construction Management and Economics, 18(4), 257-265.

[2] Deng, C. Risk management of M \& A loans for commercial banks Based on project management. Modern.

[3] Gatti, S. (2007). Measuring value-at-risk in project finance transactions. European Financial Management, 13(1), 135-158.

[4] Bu-Qammaz, A. S., Dikmen, I., \& Birgonul, M. T. (2009). Risk assessment of international construction projects using the analytic network process. Canadian Journal of Civil Engineering, 36(7), 1170-1181.

[5] Shan, X. L., \& Dai, D. S. (2009). The key risk identification of loans in project financing. Statistics and Decision, 10, 134-136.

[6] Ulucan, A., \& Atıcl, K. B. (2010). Efficiency evaluations with context-dependent and measure-specific data envelopment approaches: an application in a world bank supported project. Omega, 38, 68-83.

[7] Bouezmarni, T, Rombouts, J. (2010). Nonparametric density estimation for multivariate bounded data. Journal of Statistical Planning and Inference, 140(1), 139-152.

[8] Li, Z. J., Chi, G. T., \& Dang, J. Z. (2015). The Evaluation Model of Business Project Overall Risks of Follower Banks Based on Copula. Chinese Journal of Management Science, 23(1), 99-110.

[9] (2009). Stand \& Poor's. Global Project Finance Year Book. New York: Stand \& Poor's. 91-96.

[10] Fen, W. Q. (2002). Economic Forecasting and Decision-Making Techniques. Wuhan: Wuhan University 
Press. 324-365.

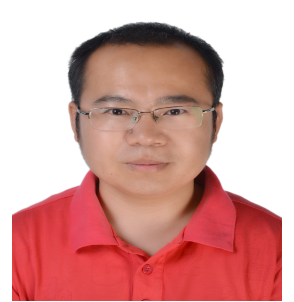

Zhanjiang Li was born in China in 1977. He got his master degree in computational mathematics from Inner Mongolia University of Technology in China. He received his doctoral degree in financial engineering from Dalian University of Technology, China. He has been teaching in Inner Mongolia Agricultural University since July, 2000 and became an associate professor in 2016. His major research interests are focused on theory and model of commercial bank risk decision, theory and model of credit evaluation, and systematic evaluation. He also published dozens of papers both in Chinese and English in domestic and international academic journals. 